\title{
Intelligent Energy Meter for Optimal Energy Utilization using Mobile Communication
}

\author{
Rohit Varshney, Sarita Sahu, Pooja Kumari, Reyasat Ali, Rajat Mehrotra
}

\begin{abstract}
The reading of energy meter is very tedious as well as an expensive job to do. The meter reading is taken manually by an individual to generate the bill, which will then passed into a software to automate billing and payment. A new network communication for the reading of energy meter by short message service (SMS) technology and software system besides the pre-existing energy meters. An Arduino will be integrated with the energy meter to read ad store the usage of energy. Energy meter gives the readings to Arduino and it sends it to the consumer via SMS. This is useful for the consumer to regularly check their power consumption and manage their energy usage according to their need and budget. The user can check their energy usage from anywhere by using their mobile phones an additional feature of load control is also provided to the user.
\end{abstract}

Keywords: Smart Energy Meter, SMS.

\section{INTRODUCTION}

In India, energy meters are vastly electromechanical by nature, and manpower is needed to take the readings of energy meters from each house and providing it to the system of the regional office, manually. Also, humans are required to control the load by cutting off the supply at the consumer end but they are gradually getting overthrown by more modern, accurate, and advanced electronic meters. A good amount of electrical power is lost due to theft at the destination. We can abolish this by making some changes in the existing meters. In regular electromechanical energy meters, electricity usage is evaluated by individual and at a particular interval, they arrange to bill on suspicion dependent on the previous records of power consumption. It is possible that the consumer has not

Revised Manuscript Received on June 24, 2020.

* Correspondence Author

Rohit Varshney*, Electrical \& Electronics Engineering, G.L. Bajaj Institute of Technology \& Management, Greater Noida, India. Email: rohit.official.97@gmail.com

Sarita Sahu, Electrical \& Electronics Engineering, G.L. Bajaj Institute of Technology \& Management, Greater Noida, India. Email: s.saritasahu144@gmail.com

Pooja Kumari, Electrical \& Electronics Engineering, G.L. Bajaj Institute of Technology \& Management, Greater Noida, India. Email: poojakumari11490@gmail.com

Reyasat Ali, Electrical \& Electronics Engineering, G.L. Bajaj Institute of Technology \& Management, Greater Noida, India. Email: reyasat123456@gmail.com

Rajat Mehrotra, Electrical \& Electronics Engineering, G.L. Bajaj Institute of Technology \& Management, Greater Noida, India. Email: rajatlmp@gmail.com

(C) The Authors. Published by Blue Eyes Intelligence Engineering and Sciences Publication (BEIESP). This is an open access article under the CC BY-NC-ND license (http://creativecommons.org/licenses/by-nc-nd/4.0/) used the power as compared to previously recorded usage for certain reasons, for example being at work for a longer period, being on a long vacation, and so on [1]. This method of charging is not proper for the power supply companies as it carries out a false record for the usual power consumption in the buyer's area and can cause blunders in upcoming arranging by the companies. Over the years, energy meters have gone through changes of enhancement and came out to be extra complicated with other capacities. Electromechanical meters are adjacent to no correctness and are deprived of any configurability. We already have a prepaid metering system in certain areas of India but the observing system is hardly accessible and because the required units of power are needed to be purchased before the consumption, the consumers might settle the unit measurement which they require to buy and due to this the continuous power isn't ensured. The system which is proposed is an alternate for the conventional electromechanical meter reading strategies and can provide remote access to existing meters for professionals. It can check upon meter readings without anyone going to each house. A GSM module is integrated into the energy meters to remotely check the power usage and provide a remote framework. It can monitor the readings from meter continuously without visiting the energy meter. This will reduce human efforts and can be controlled easily [2].

\section{LITERATURE REVIEW}

In recent times, new improvements have brought many changes to increase energy services. But there are more issues in the system which influence the style of administrations and due to this the amount of fulfillment of consumers. In [3] R. Bhavani and S. Alagammal used the existing system, forgetting the energy utilization it uses manual meter perusing. The current system of energy metering and billing depends upon electromechanical and digital meters. It requires more human resources and time. Some of the disadvantages of it are the requirement of extra manpower, the possibility of wrong controlling of energy consumption. The system which is proposed evaluates old methods drawbacks and current methods and technologies with a computerized system to receive or control readings of energy meter and providing consumers with the facilities of continuously monitoring the energy consumption. B. Karimi et al. [4] proposed a system that uses a GSM module along with Arduino/microcontroller at the user end. Such meters can provide the energy meter readings to remote areas whenever required. It also includes the method of load control. In this system, the traditional domestic energy meter is used along with the electronic devices and sensors to provide a wireless system that requires very little 


\section{Intelligent Energy Meter for Optimal Energy Utilization using Mobile Communication}

human interference and can be controlled or operated remotely via mobile phones. Meters with an automatic meter reading system provide meter readings, load control, and giving information about consumed energy to the customer whenever it is required by the consumer through SMS. This system is designed to provide telemetering and user can disconnect service whenever required, this will save power for the user and the as well.

\section{SYSTEM DESIGN}

This system works together with the pre-existing energy meters and provides the consumers with real-time energy readings. This system is cost-effective, robust, and have low-power characteristics due to which it can be used in homes widely. This system is the collaboration of pre-existing energy meters and new electronic devices and sensors [5]. This system is used to screens the parameters of energy meter and then calculates the number of electrical units consumed. The system can be controlled according to the requirements of the user.

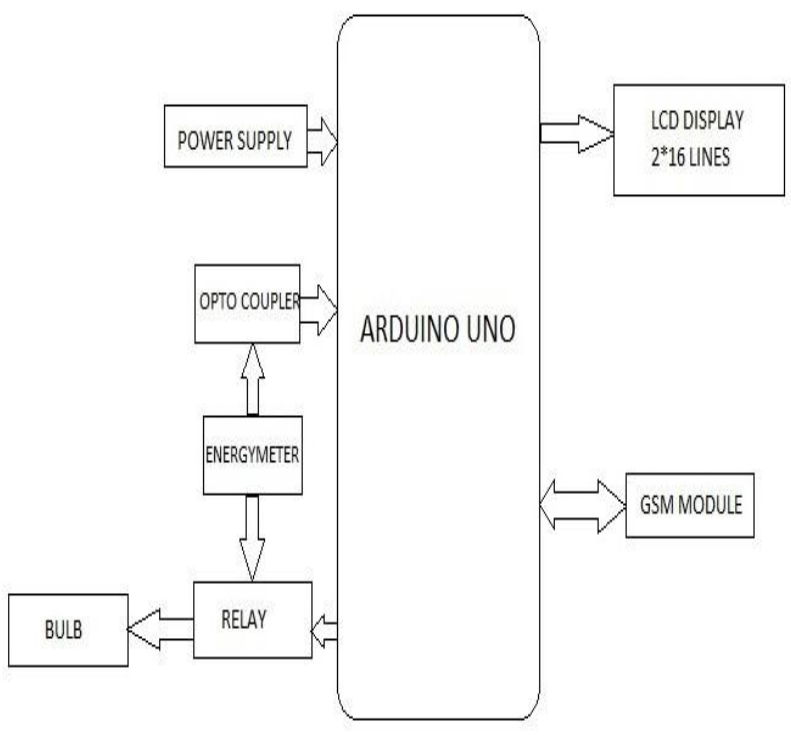

Fig. 1.Block diagram of the system

\section{Methodology}

The system which is proposed uses microcontroller Arduino Uno, it can process the commands according to our need such as power supplied to appliances or proving readings from the energy meter. The control signal which is generated by the GSM module via the SMS from the consumer is forwarded to the Arduino Uno which operated the appliances connected to the energy meter through the relay. The energy meter which is connected to the Arduino Uno through optocoupler will check and calculate the unit consumption. Arduino Uno will get the number of units consumed at regular intervals from the energy meter via optocoupler and then calculate the billing amount and provide it to the consumer whenever required by the user. The same information will be displayed on LCD [6]. The power consumption could be reduced by switching offloads through the specified commands. The whole system provides a swift, easy, and effortless experience. The hardware requirements of the proposed system are Arduino Uno microcontroller, energy meter, optocoupler (for connecting energy meter to the microcontroller), GSM module (to exchange data between consumer and microcontroller), LCD and relay. The proposed meter records the power consumption and calculates the bill. It works based on the blinks of the calibration LED which is found inside the traditional electromechanical meter. An optocoupler that contains an IR diode and phototransistor, is incorporated in the system to detect the number of blinks of calibration LED by connecting both of them. Whenever the calibration LED blinks the electricity flows through the optocoupler's IR diode. The IR radiation from the IR diode is sensed by the photodiode which then sends the signal to the Arduino[7].

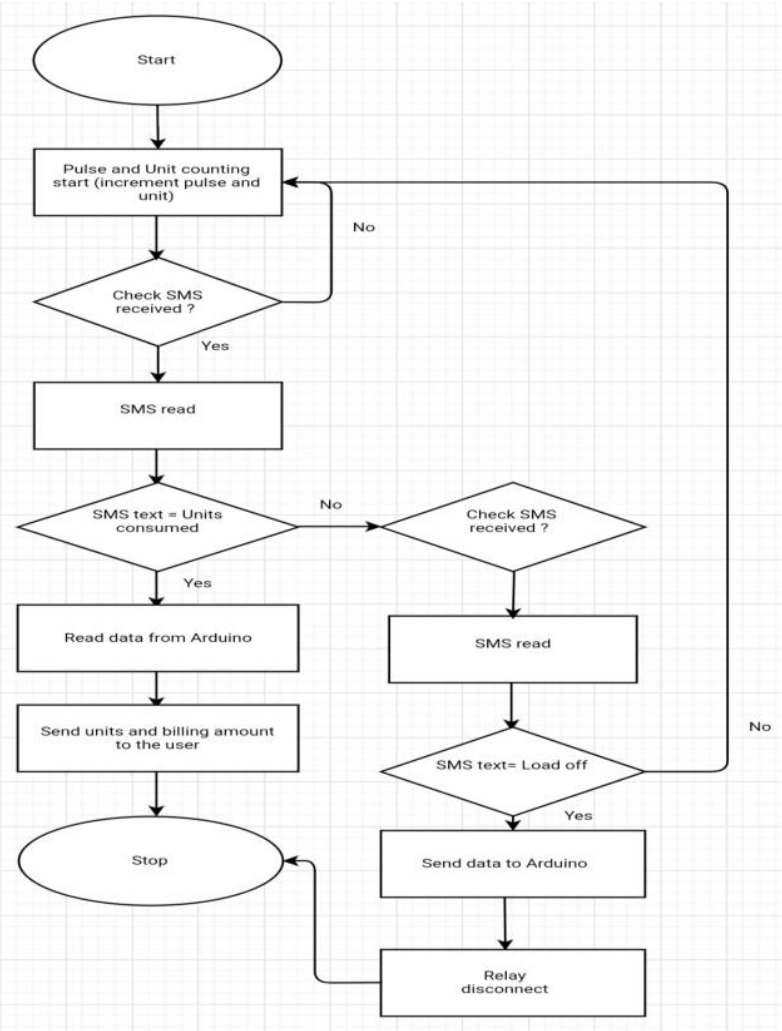

Fig. 2.Flowchart of the process

\section{HARDWARE COMPONENTS}

Arduino Uno: It is a single-board microcontroller board based on microchip ATmega328P. It has 14 digital I/O pins and 6 analogs I/O pins and can be programmed with Arduino IDE. It can be powered by an external battery, external power supply adapter, or via USB type B cables.

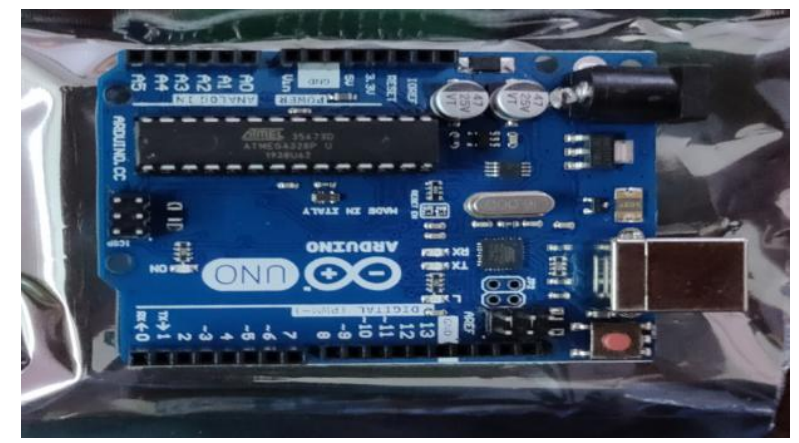

Fig. 3.Arduino Uno

ublished By:

Blue Eyes Intelligence Engineering \& Sciences Publication (C) Copyright: All rights reserved. 
Relay: Relay is like a switch which is electrically operated. It consists of several inputs terminals for one or multiple control signals. Many relays have electromagnetic coils to mechanically operate a switch, but there are many other principles which are also used to operate relays. In the proposed system we use relays to connect the load to Arduino Uno and energy meter.

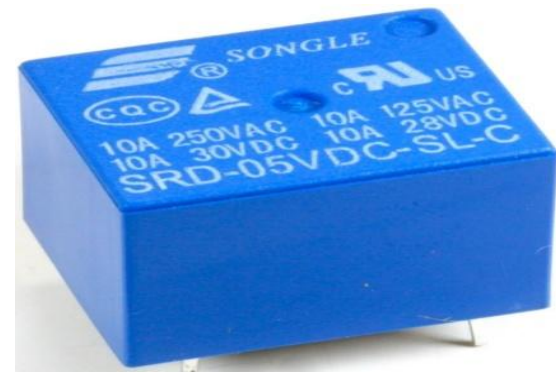

Fig. 4.Relay

GSM Module: GSM is a standard developed by the European Telecommunication Standards Institute. It describes the protocol for the coactivity of mobile y using cellular networks. We will use it to send data from mobile to Arduino Uno. We can switch loads on/off by the commands given by the mobile.

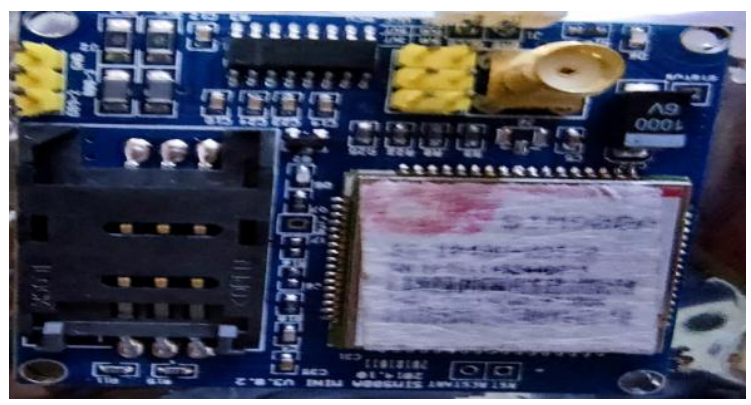

Fig. 5.GSM Module for Mobile Communication.

Optocoupler: It is a combination of light-emitting and light-sensing devices. The signal is applied to the light-emitting device (LED), then it falls on the light-sensing device (Photodiode, LDR, etc.).

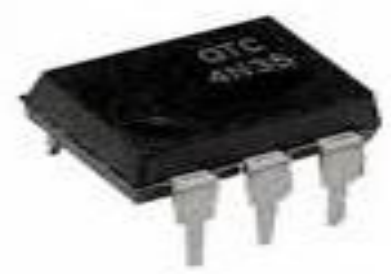

Fig. 6.Optocoupler.

\section{PROPOSED SYSTEM}

In this system, a microcontroller has been used to collect readings from energy meter via a combination of optocoupler and Arduino and send it to the user's mobile via GSM module. Hence, the user can look for his/her energy consumption at any time and regulate it according to himself/herself. A smart meter works by wireless communication between energy meter and consumer so that consumers will always have the real-time electricity usage data and will also be able to control the load remotely [8].
Hence, reducing power wastage. In this system, optocoupler interacts with energy meter though the calibration LED of energy meter. Whenever the calibration LED blinks, the electricity flows through optocoupler (as they are connected). This results in the activation of IR diode inside optocoupler which then sends IR radiation to the photodiode. Then photodiode sends the signal to the Arduino Uno to calculate the number of units used. The microcontroller then generates the bill according to the use and sends it to the user whenever asked by the user [9].

To get the information about bill user is required to send specified text via SMS from his her mobile phone. This SMS is received by the GSM module and further transferred to the Arduino Uno. Then the microcontroller reads the message and generates the bill according to the units consumed by the user and sends this information to the user's mobile phone with the help of the GSM module in the form of SMS [10]. Relays are also used to control the load flow and are operated through the signal from a microcontroller whenever the user sends the command to do so. After connecting the Arduino and GSM module and other peripherals with each other, connect the electricity meter to the load through a relay. Arduino checks for the SMS from the user. As soon as the user sends the SMS with the specified text of disconnecting the load, Arduino Uno reads it and then sends the signal to activate the relays. As a result, relays disconnect the load from the energy meter, hence disconnecting the load from the main power supply [11].

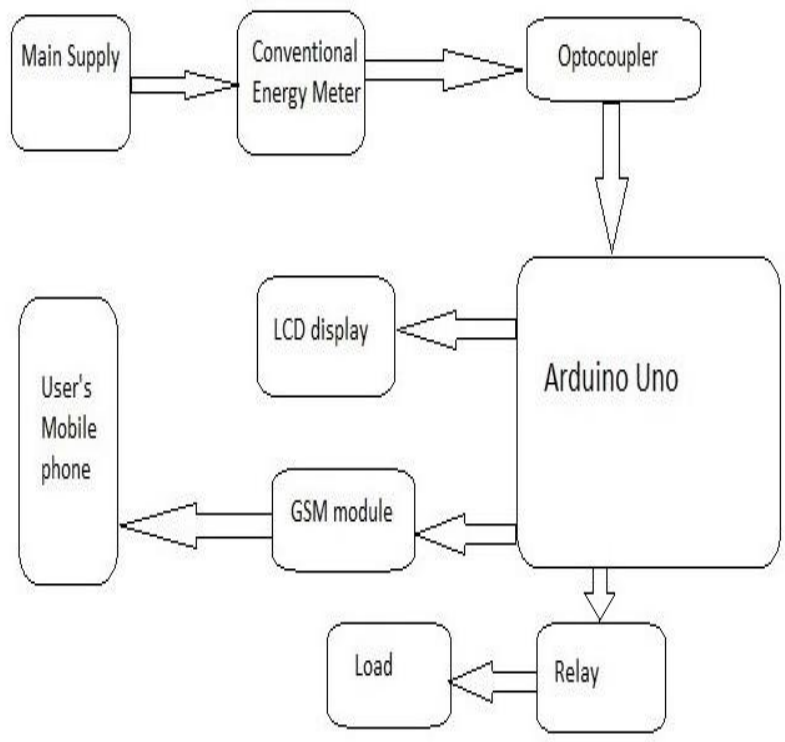

Fig. 7.Complete Structure of the Proposed System.

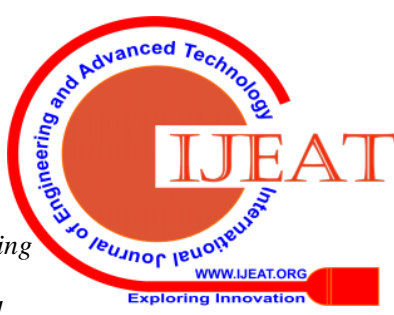




\section{Intelligent Energy Meter for Optimal Energy Utilization using Mobile Communication}

Table- I: Difference between Conventional \& Proposed Metering System

\begin{tabular}{ccc}
\hline Type & Conventional Meter & Proposed Design \\
\hline Communication & None & GSM \\
Payment & Postpaid & Postpaid/ \\
& Prepaid \\
Data Display & Units & Units, Bill \\
User Interface & Gear based display & LCD \\
Load Control & No Control & Relay Control \\
Data Collection & Manual & SMS \\
Cost & $1 \mathrm{~K}$ & Around 2K \\
\hline
\end{tabular}

\section{CONCLUSION}

Through this project, we have created a prototype of a smart system that will provide an effective, efficient, and quick path to check and regulate the energy consumption at the user end. This will help users to regulate energy consumption according to their needs and save their money and energy. Users will be able to remotely switch the load on/off via their mobile. This paper concludes by creating a user-friendly and long-lasting system.

\section{REFERENCES}

1. M. Patel Umang and M. Modi Mitul, "A Review on Smart Meter System", International of Innovative Research in Electrical, Electronics, Instrumentation and Control Engineering, Vol. 3, No. 12, December 2015.

2. Subhashis Maitra, "Embedded Energy Meter- A new concept to measure the energy consumed by a consumer and to pay the bill", Power System Technology and IEEE Power India Conference, 2008.

3. R. Bhavani and S. Alagammal, "Design and Implementation of GSM Based Energy Smart Meter for Home Applications", International Journal of Latest Trends in Engineering and Technology, Vol. 8 No. 1, pp. 431-439, 2015.

4. B. Karimi, V. Namboodiri, M. Jadliwala, "On the scalable collection of metering data in smart grids through message concatenation", Proc. 4th IEEE International Conference Smart Grid Communication, pp. 318-323, Oct, 2013.

5. An Approach to Automate Power Meter Reading \& Billing System, Alok Malviya, Global Journal of Management and Business Studies. ISSN 2248-9878 Volume 3, Number 9 (2013), pp. 934-948@ Research India Publications.

6. G.L. Prashanthi, K.V. Prasad, "Wireless power meter monitoring with theft detection and intimation system using GSM and Zigbee networks", Journal of Electronics and Communication Engineering, vol. 9, no. 6, Nov - Dec. 2014

7. Design and implementation of smart energy meter by V. Preethi, G. Harish, 2016 International Conference on Inventive Computation Technologies (ICICT).

8. K Ashna, Sudhish N George, "GSM Based Automatic Energy Meter Reading System with Instant Billing".

9. Najmus Saqib Malik, Fredrich Kupzog, Michael Sonntag, "An approach to secure mobile agents in automatic meter reading", IEEE International Conference on Cyber worlds computer society, pp. 187-193, 2010.

10. A. Abdollahi, M. Dehghani, N. Zamanzadeh, "SMS- based reconfigurable automatic meter reading system", IEEE International

11. Conference on Control Applications (CCA 2007), pp. 1103-1107, Oct, 2007.

12. Jennifer Bray \& Charles F. Strutman, "Bluetooth 1.1 Connect Without Cables", Second Edition, Prentice Hall 2001. http://ieeexplore.ieee.org/documents/6750333/

\section{AUTHORS PROFILE}

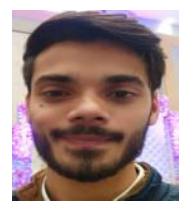

Rohit Varshney is doing his final year B.tech. (EN) form GL Bajaj Institute of Technology \& Management Greater Noida, UP, India. His final project is is "Intelligent Energy Meter for Optimal Energy Utilization Using Mobile Communication"

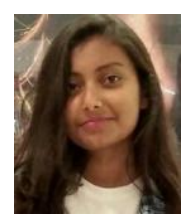

Sarita Sahu is doing her final year B.tech. (EN) form GL Bajaj Institute of Technology \& Management Greater Noida, UP, India. Her final project is is "Intelligent Energy Meter for Optimal Energy Utilization Using Mobile Communication"

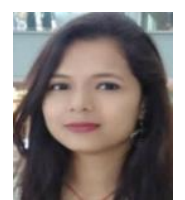

Pooja Kumari is doing her final year B.tech. (EN) form GL Bajaj Institute of Technology \& Management Greater Noida, UP, India. Her final project is is "Intelligent Energy Meter for Optimal Energy Utilization Using Mobile Communication"

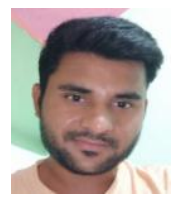

Reyasat Ali is doing his final year B.tech. (EN) form GL Bajaj Institute of Technology \& Management Greater Noida, UP, India. His final project is "Intelligent Energy Meter for Optimal Energy Utilization Using Mobile Communication"

Rajat Mehrotra is an Assistant Professor in the department of Electrical \& Electronics Engineering at GL Bajaj Institute of Technology \& Management, Greater Noida, UP, India. He received his B.Tech. degree in Electrical \& Electronics Engineering from Dr. A.P.J. Abdul Kalam Technical University, Lucknow (Formerly UPTU), in 2008 and M.Tech. degree in Telecommunication Engineering from the same university, in 2014. His research interests are in digital image processing, Biomedical Imaging and Deep Learning. He has published various papers in journals and conferences of national and international repute.

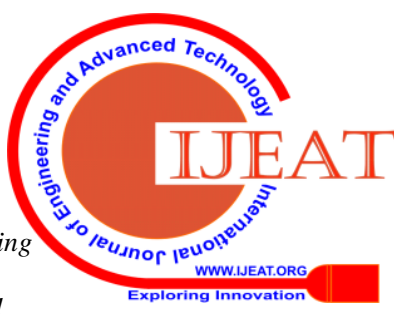

